\title{
Pemberian Insulin pada Diabetes Melitus Tipe-1
}

\author{
Wisman, Hakimi, Charles D. Siregar, Melda Deliana \\ Bagian Ilmu Kesehatan Anak Fakultas Kedokteran, Universitas Sumatera Utara/ RSUP H. \\ Adam Malik Medan
}

\begin{abstract}
Abstrak. Pemberian insulin pada diabetes mellitus (DM) tipe-1 merupakan keharusan karena belum ada terapi lain yang dapat dipakai dalam mengobati DM tipe-1. Pedoman untuk menentukan kebutuhan insulin berdasarkan berat badan, usia, dan status pubertas. Beberapa faktor mempengaruhi keberhasilan pengobatan DM tipe-1, belum ada keseragaman dalam terapi insulin baik dalam jenis, dosis maupun regimen yang dipakai. Untuk mencapai kontrol metabolik yang optimal, mendapatkan dampak insulin yang diharapkan, serta mengurangi kejadian komplikasi seminimal mungkin tanpa mengabaikan kualitas hidup pasien, maka pada keadaan tertentu diperlukan penyesuaian dosis insulin, regimen, maupun teknik dan lokasi penyuntikan (Sari Pediatri 2007; 9(10):48-53).
\end{abstract}

Kata kunci: diabetes mellitus tipe-1, insulin

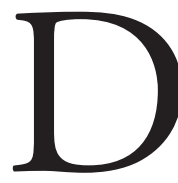
efinisi diabetes adalah hiperglikemia kronik yang disebabkan oleh defisiensi insulin baik absolut maupun relatif. ${ }^{1-4}$ Secara klinis, diabetes melitus (DM) dibedakan atas empat bentuk yaitu (1) DM tipe-1 yang sebelumnya sering disebut dengan insulin dependent diabetes melitus (IDDM) atau diabetes melitus juvenil, (2) DM tipe-2 atau non-insulin dependent diabetes melitus (NIDDM) yang umumnya terjadi setelah dewasa, (3) DM oleh karena penyebab lain, dan (4)

\footnotetext{
Alamat korespondensi

Dr. Melda Deliana, SpA(K). Bagian Ilmu Kesehatan Anak, Fakultas Kedokteran Universitas Sumatera Utara/ RSUP H.Adam Malik, Jl. Bunga Lau no. 17 Medan.

Telepon: 0618361721 - 8365663 Fax.: 0618361721

E-mail: bikafkusu@telkom.net ; kotak Pos 697 Medan - 20136
}

DM selama masa kehamilan. ${ }^{3-5}$

Diagnosis DM dapat ditegakkan apabila memenuhi kriteria berikut, ${ }^{3,4}$

1. Ditemukannya gejala klinis poliuria, polidipsia, berat badan yang menurun, dan kadar glukosa darah sewaktu $3200 \mathrm{mg} / \mathrm{dL}(11.1 \mathrm{mmol} / \mathrm{L})$ atau

2. Kadar glukosa darah puasa ${ }^{3} 126 \mathrm{mg} / \mathrm{dL}(7.0$ $\mathrm{mmol} / \mathrm{L})$. Puasa adalah tidak mengkonsumsi kalori sekurang-kurangnya 8 jam atau

3. Kadar glukosa darah 2 jam setelah uji toleransi glukosa oral (OGTT) dengan 75 gram glukosa 3 $200 \mathrm{mg} / \mathrm{dL}(11.1 \mathrm{mmol} / \mathrm{L})$.

Diabetes mellitus tipe-1 adalah DM yang terjadi akibat proses autoimun yang merusak sel-b pankreas sehingga produksi insulin berkurang bahkan terhenti. ${ }^{1,3-}$ 7 Anak atau remaja dengan DM tipe-1 mempunyai riwayat poliuria, polidipsia, polifagia dan penurunan berat badan selama beberapa minggu dengan disertai 
hiperglikemia, glikosuria, ketonemia, dan ketonuria.,

Insidens DM tipe-1 sangat bervariasi. Insidens tertinggi terdapat di Finlandia yaitu 40 / 100.000 populasi dan terendah di Karachi (Pakistan) 0,7 / 100.000 populasi. Puncak insidens DM tipe-1 berada pada dua golongan usia, yaitu 5-6 tahun dan usia pubertas. ${ }^{1,3,5-11}$

Sasaran pengelolaan DM tipe-1 pada anak meliputi bebas gejala penyakit, dapat menikmati kehidupan sosial, dan terhindar dari komplikasi. Tujuan pengobatan untuk mencapai tumbuh kembang optimal, perkembangan emosional normal, kontrol metabolik yang baik, jarang absen sekolah, pasien tidak memanipulasi penyakit, dan akhirnya mampu mandiri mengelola penyakitnya. ${ }^{5,8,9,12}$ Patokan kadar glukosa darah dan HbAlc yang diharapkan sebagai tujuan pengobatan DM tipe-1 sesuai umur anak tercantum dalam Tabel 1.

Untuk mencapai sasaran dan tujuan tersebut, komponen pengelolaan DM tipe-1 meliputi pemberian insulin, pengaturan makan, olah raga, edukasi dan pemantauan mandiri. ${ }^{3,5,8,9}$

Tujuan terapi insulin untuk menghilangkan gejala hiperglikemia, mencegah terjadinya diabetik ketoasidosis dan koma, mengembalikan masa tubuh, perbaikan kapasitas olah raga dan tampilan kerja, menurunkan frekuensi infeksi, serta mencegah komplikasi jangka panjang. ${ }^{13}$

Tujuan penulisan untuk membahas masalah pemilihan jenis insulin, regimen insulin, penyesuaian dosis insulin, teknik, dan lokasi penyuntikan insulin pada DM tipe-1.

\section{Insulin}

Sampai saat ini insulin merupakan obat yang harus selalu tersedia untuk semua kasus DM tipe-1 karena alternatif obat selain insulin masih dalam taraf penelitian. ${ }^{1,3,5,8}$ Perlu dicermati, karena penghentian insulin satu kali dalam satu minggu dapat menurunkan kontrol metabolik. ${ }^{14}$

Insulin adalah suatu hormon polipeptida yang dihasilkan oleh sel-sel pulau Langerhans pankreas yang mempunyai dampak regulasi glukosa. Insulin menghambat proses glikogenolisis di hati dan glukoneogenesis di hati dan ginjal serta merangsang pengambilan glukosa oleh otot dan jaringan lemak. Insulin juga menghambat lipolisis dan proteolisis di jaringan. Di hati, insulin juga menekan proses ketogenesis, sehingga defisiensi insulin dapat menyebabkan terjadinya ketosis. ${ }^{1,6,12,13}$

\section{Jenis insulin}

Terdapat 4 jenis insulin yang biasa digunakan pada pengobatan DM tipe-1, yaitu (1) insulin kerja ultra pendek, (2) insulin kerja pendek, (3) insulin kerja menengah, serta (4) insulin kerja panjang. ${ }^{3,5,8,10,13}$ Tidak ada kesepakatan atau aturan baku untuk menentukan jenis insulin mana yang paling sesuai bagi seorang pasien DM tipe-1, Namun sebagian besar ahli sepakat bahwa insulin kerja panjang kurang sesuai digunakan pada anak. ${ }^{5,8}$ (Tabel 2)

\section{Insulin kerja ultra pendek (rapid acting insulin)} Terdapat dua macam analog insulin kerja ultra pendek, yaitu insulin Lispro dan insulin Aspart. Insulin kerja ultra pendek mempunyai daya absorpsi pada tempat suntikan lebih cepat (90\% dalam 100 menit) dibandingkan regular insulin (90\% dalam 150 menit). Awitan kerja lebih cepat, puncak konsentrasi lebih tinggi dan lebih dini, serta lama kerja lebih singkat. Lispro dapat diberikan 15 menit sebelum makan dan digunakan pada tata laksana diabetes ketika sakit. ${ }^{5,8,10}$

\section{Insulin kerja pendek (short acting insulin)}

Potensi dan efek hipoglikemia insulin kerja pendek atau insulin regular, hampir sama dengan insulin kerja ultra pendek. Selain dapat diberikan subkutan, insulin regular adalah insulin yang dapat diberikan secara intra vena, oleh karena itu insulin ini biasanya dipakai

Tabel 1. Nilai kadar glukosa darah dan HbA1c yang diharapkan pada DM tipe-1 ${ }^{3}$

\begin{tabular}{lccc}
\hline \multirow{2}{*}{ Umur (tahun) } & \multicolumn{2}{c}{ Rentang kadar glukosa darah $(\mathrm{mg} / \mathrm{dl})$} & \multirow{2}{*}{ HbA1c (\%) } \\
\cline { 2 - 3 } & Sebelum makan & Waktu tidur/malam & \\
\hline Pra sekolah $(<6)$ & $100-180$ & $110-200$ & $<8,5(>7,5)$ \\
Usia sekolah $(6-12)$ & $90-180$ & $100-180$ & $<8$ \\
Remaja dan dewasa muda (>12-19) & $90-130$ & $90-150$ & $<7,5$ \\
\hline
\end{tabular}


Tabel 2. Jenis insulin ${ }^{10}$

\begin{tabular}{|c|c|c|c|c|}
\hline Jenis & Tipe insulin & $\begin{array}{l}\text { Awitan } \\
\text { (jam) }\end{array}$ & $\begin{array}{l}\text { Puncak kerja } \\
\quad \text { (jam) }\end{array}$ & $\begin{array}{l}\text { Lama kerja } \\
\quad \text { (jam) }\end{array}$ \\
\hline Kerja ultra pendek & Insulin, lispro, insulin, aspart & 5-15 menit & $1-1,5$ & $3-4$ \\
\hline Kerja pendek & Regular, velosulin & 15-30 menit & $1-3$ & $5-7$ \\
\hline Kerja menengah & $\begin{array}{l}\text { Lente, neutral protamine } \\
\text { Hagedorn (NPH) }\end{array}$ & $2-4$ & $8-10$ & $18-24$ \\
\hline Kerja panjang & $\begin{array}{l}\text { Ultralente, } \\
\text { Ins. glargine }\end{array}$ & $\begin{array}{l}4-5 \\
6-8\end{array}$ & $\begin{array}{c}8-14 \\
-\end{array}$ & $\begin{array}{c}25-36 \\
24\end{array}$ \\
\hline
\end{tabular}

untuk mengatasi keadaan akut seperti ketoasidosis, pasien baru, dan tindakan bedah. ${ }^{10}$ Pada kasus DM tipe-1 yang masih balita sebaiknya menggunakan insulin jenis ini untuk menghindari efek hipoglikemia.

\section{Insulin kerja menengah}

Insulin kerja menengah mempunyai awitan yang lambat dan masa kerja yang panjang tetapi masih tetap kurang dari 24 jam. Insulin jenis ini dapat digunakan dua kali sehari, ${ }^{10}$ digunakan untuk anak yang telah mempunyai pola hidup lebih teratur untuk menghindari terjadinya episode hipoglikemia. Sebagian besar kasus DM tipe-1 pada anak menggunakan insulin kerja menengah.,

\section{Insulin kerja panjang}

Mengingat masa kerja yang panjang, maka pemakaian insulin ini cukup diberikan satu kali dalam satu hari. ${ }^{5,8}$ Pada suatu penelitian disebutkan bahwa pemakaian insulin kerja panjang secara bermakna mengurangi kejadian hipoglikemia pada malam hari (nocturnal hypoglycemia). Pemakaian insulin kerja panjang (glargine insuline) juga secara bermakna dapat menurunkan kadar HbA1c serta frekuensi terjadinya hipoglikemia. ${ }^{10,15}$ Percampuran insulin kerja ultra pendek dengan insulin kerja panjang tidak terbukti lebih baik dalam mencegah nocturnal hypoglycemia. ${ }^{16,17}$

\section{Insulin Campuran}

Untuk kemudahan dan pencapaian kadar terapeutik yang adekuat, insulin regular dengan insulin kerja menengah dapat dicampur dalam satu alat suntik, kemudian disuntikkan secara subkutan dalam dosis terbagi sebelum sarapan pagi dan makan malam. Dianjurkan untuk memasukkan insulin regular terlebih dahulu ke dalam alat suntik sebelum memasukkan insulin kerja menengah. ${ }^{5,8,10}$

Insulin campuran yang stabil (70\% insulin kerja menengah dengan 30\% insulin kerja pendek) yang sudah dikemas oleh pabrik, tersedia untuk memudahkan pasien yang kesulitan dalam mencampur sendiri insulin atau kurang terampil. Termasuk insulin campuran diantaranya Novolin ${ }^{\circledR} 70: 30$ yang merupakan campuran $70 \%$ insulin kerja menengah dengan 30\% insulin regular, dan Humulin ${ }^{\circledR}$ 70:30. Pemakaian preparat ini dianjurkan bagi pasien yang sudah dapat mengontrol metabolik dengan baik. ${ }^{5}$

Kebutuhan insulin diukur berdasarkan berat badan, usia, dan status pubertas anak. Anak yang baru didiagnosis DM tipe-1 mendapatkan dosis inisial 0,5-1,0 unit/kg per hari. Dosis lebih besar diberikan pada anak yang menderita ketoasidosis, pemakaian steroid, serta pada saat pubertas. Sementara dosis yang lebih kecil dibutuhkan pada honeymoon period, saat kebutuhan menurun sampai di bawah dosis inisial. ${ }^{3-5,10}$

\section{Regimen insulin}

Terdapat tiga jenis regimen insulin dalam penanganan DM tipe-1 yaitu sistem konservatif, sistem intensif, dan sistem basal bolus. ${ }^{5,8,10}$ Sistem konservatif adalah pemberian insulin 2 atau 3 kali perhari dengan pemantauan kadar gula darah di rumah yang longgar / tidak rutin, kontrol ke dokter setiap tiga bulan, dan tidak dapat mengubah dosis insulin sesuka hati. Sistem intensif berarti pemberian insulin minimal empat kali sehari disertai dengan pemantauan glukosa darah di rumah juga minimal empat kali sehari. Sistem basal bolus adalah pemberian insulin kerja panjang ${ }^{3}$ atau kerja menengah sebelum tidur malam (komponen basal) dan kemudian pemberian insulin kerja pendek setiap kali sebelum makan. ${ }^{5}$ Dosis komponen basal 
$30 \%-40 \%$ dari total dosis insulin perhari dan sisanya dibagi rata untuk komponen bolus. ${ }^{5,8,10}$ Regimen basal bolus dengan insulin pump merupakan regimen yang paling mendekati kebutuhan insulin fisiologis. ${ }^{8}$ Regimen insulin pump terbukti aman, efektif, mencapai kontrol metabolik yang baik, serta efek samping berupa episode hipoglikemia yang minimal. ${ }^{18-}$

${ }^{22}$ Regimen lain yang juga terbukti efektif dalam mencapai kontrol gula darah yang baik namun masih sangat jarang dilakukan adalah inhaled insulin. ${ }^{23}$

\section{Penyesuaian dosis insulin}

Penyesuaian dosis insulin bertujuan untuk mencapai kontrol metabolik yang optimal tanpa mengabaikan kualitas hidup pasien baik jangka panjang maupun jangka pendek dengan pengaturan dosis insulin yang tidak terlalu kaku maupun terlalu fleksibel. Penyesuaian dosis dibutuhkan pada honeymoon period, masa remaja, masa sakit, saat operasi, dan saat berpuasa. ${ }^{5}$

\section{Honeymoon period}

Pada perjalanan penyakitnya, DM tipe-1 sering ditandai dengan fase remisi yang dikenal dengan honeymoon period. Saat honeymoon period anak sering mengalami serangan hipoglikemia sehingga kebutuhan akan insulin harus dikurangi, bahkan pada beberapa kasus keadaan metabolik terkontrol tanpa pemberian insulin sama sekali. Dosis insulin pada saat ini perlu disesuaikan untuk menghindari serangan hipoglikemia, lebih rendah dari terapi inisial (0,3 U/kg perhari). ${ }^{3-5,8,10}$

\section{Masa remaja}

Pada masa remaja, kebutuhan insulin meningkat karena kerja hormon seks steroid, terjadi peningkatan amplitudo dan frekuensi sekresi growth hormone, yang merupakan hormon anti insulin, serta oleh karena kebiasaan remaja suka makanan jajanan atau kudapan. ${ }^{3-5,8,10}$

\section{Saat sakit}

Pada saat sakit, dosis insulin perlu disesuaikan dengan asupan makanan tetapi jangan menghentikan insulin sama sekali, karena dapat meningkatkan lipolisis dan glikogenolisis sehingga kadar glukosa darah meningkat dan pasien rentan untuk menderita ketoasidosis. ${ }^{5,8,10}$

\section{Operasi}

Tindakan operasi emergensi sebaiknya ditunda pada keadaan kadar glukosa tidak stabil atau pada pasien ketoasidosis sampai keadaan membaik dan stabil, kecuali ada indikasi klinis absolut. Pada tindakan operasi elektif, anak sebaiknya berada dalam kontrol metabolik yang baik. ${ }^{5,8,10}$

\section{Puasa}

Pada bulan puasa, pasien DM tipe-1 dapat melakukan ibadah puasa dengan syarat kontrol metabolik baik. Pemberian insulin disesuaikan dengan waktu makan (sahur dan buka puasa). Perlu diperhatikan jarak waktu antara bersahur dan berbuka pada penentuan dosis dan jenis insulin yang digunakan. ${ }^{5}$

\section{Olahraga}

Olahraga membantu kerja metabolisme tubuh sehingga dapat mengurangi kebutuhan insulin. Olahraga dan exercise berhubungan dengan 10\%$20 \%$ kejadian episode hipoglikemi pada anak. Kadar glukosa darah $<100 \mathrm{mg} / \mathrm{dl}$ selama olahraga atau exercise memerlukan penambahan asupan karbohidrat 15 gram. Pada olahraga atau exercise yang terencana dengan baik, penurunan dosis insulin lebih disukai dari pada penambahan jumlah kalori. ${ }^{5,8,10}$

\section{Efek Somogyi dan fenomena Down}

Kedua fenomena ini mengakibatkan hiperglikemia pada pagi hari. Pada efek Somogyi terjadi akibat pemberian insulin yang berlebihan pada malam hari, maka terjadi hipoglikemia sehingga tubuh berupaya mengatasinya dan berakibat terjadi hiperglikemia. ${ }^{3,5,6,8}$ Hal ini ditanggulangi dengan mengurangi dosis insulin pada malam hari atau pemberian makanan kecil sebelum tidur. Sedangkan pada fenomena Down hiperglikemia terjadi akibat kerja hormon anti insulin karena peningkatan hormon pertumbuhan nocturnal, peningkatan resistensi insulin dan peningkatan produksi glukosa hati. ${ }^{3,5,6,8}$ Pada keadaan ini dosis insulin harus ditambah. ${ }^{5,8}$

\section{Teknik dan lokasi penyuntikan insulin}

Terdapat beberapa faktor yang mempengaruhi penyerapan insulin. Faktor-faktor yang mempengaruhi penyerapan insulin adalah lokasi penyuntikkan (dinding perut tercepat, kemudian berturut-turut lengan, paha, dan bokong), kedalaman penyuntikkan (suntikan intra muskular akan mempercepat absorpsi), jenis insulin, dosis 
insulin (dosis kecil diabsorpsi lebih cepat), kegiatan fisik, ada tidaknya lipodistrofi atau lipohipertrofi (keadaan ini akan memperlambat absorpsi), dan perbedaan suhu (suhu tinggi akan mempercepat absorpsi).,

Insulin harus disuntikkan secara subkutan dalam dengan melakukan pinched (cubitan) dan jarum suntik harus membentuk sudut $45^{\circ}$, atau $90^{\circ}$ apabila jaringan subkutannya tebal. ${ }^{5,8}$ Tempat penyuntikkan dapat dilakukan di abdomen, paha bagian depan, pantat, dan lengan atas. Penyuntikan dapat dilakukan di daerah yang sama setiap hari, tetapi tidak dianjurkan di titik yang sama. Sebaiknya dilakukan rotasi tempat penyuntikan. Penyuntikan insulin kerja cepat dianjurkan di daerah abdomen sedangkan insulin kerja menengah di daerah paha dan bokong. ${ }^{5,8}$

\section{Kontrol metabolik}

Kontrol metabolik sebagai tujuan utama pengobatan pasien DM berguna untuk mengurangi terjadinya komplikasi. Sebaiknya kontrol metabolik tidak sematamata didasarkan pada pemeriksaan klinis, tetapi juga diikuti dengan pemeriksaan laboratoris (Tabel 3). 3,5,10 endocrinology: the requisites in pediatrics. Pennsylvania: Elsevier Mosby; 2005.h.3-18.

2. Diabetes mellitus. Dalam: Felig P, Baxter JD, Broadus AE, Frohman LA, penyunting. Endocrinology and metabolism. Edisi ke-2. New York: McGraw-Hill; 1987. h.1092-139.

3. American Diabetes Association: Standards of medical care in diabetes (position statement). Diabetes Care 2005; 28(supplement I):S4-S36.

4. Silverstein J, Klingensmith G, Copeland K. Care of children and adolescents with type 1 diabetes: a statement of the American Diabetes Association. Diabetes Care 2005; 28:186-212.

5. Trijaya B, Batubara JR, penyunting. Konsensus nasional pengelolaan diabetes mellitus tipe-1 di Indonesia. UKK Endokrinologi IDAI. Jakarta 2000.

6. Amiel SA, Buchanan CR. Diabetes mellitus. Dalam: Brook CGD, Hindmarsh PC, Jacobs HS, penyunting. Clinical pediatric endocrinology. Edisi ke-2. London: Blackwell science; 2001.h.411-33.

7. Diabetes mellitus. Dalam: Styne DM, penyunting. Pediatric endocrinology. Philadelphia : Lippincott, 2004. h.218-47.

8. Pulungan AB. Pengobatan insulin pada diabetes mellitus tipe-1. Disampaikan pada paralel symposium 4: endocrinology. Jakarta 2002.

Tabel 3. Sasaran metabolik pada DM tipe-1 ${ }^{5}$

\begin{tabular}{lcccc}
\hline \multicolumn{1}{c}{ Target metabolik } & Baik sekali & Baik & Sedang & Kurang \\
\hline Preprandial $(\mathrm{mg} / \mathrm{dl})$ & $<120$ & $<140$ & $<180$ & $>180$ \\
Postprandial $(\mathrm{mg} / \mathrm{dl})$ & $<140$ & $<200$ & $<240$ & $>240$ \\
Urin reduksi & - & - & $-/+$ & $>+$ \\
HbAlc $(\%)$ & $<7$ & $7-7,9$ & $8-9$ & $>10$ \\
\hline
\end{tabular}

Secara laboratoris kontrol metabolik dapat dinilai dari hasil pemantauan di rumah (urin atau darah) dan HbA1c darah. Pemeriksaan kadar HbA1c wajib dilakukan setiap 3 bulan sekali dan merupakan satusatunya pemeriksaan yang dapat memberikan evaluasi kadar glukosa darah rata-rata selama 3 bulan terakhir. ${ }^{5}$ Dengan pemantauan kadar glukosa darah dapat diperkirakan terjadinya hipoglikemia sehingga tidak berkembang ke arah komplikasi yang lebih parah. ${ }^{24}$

\section{Daftar Pustaka}

1. Weinzimer S, Magge S. Type 1 diabetes mellitus in children. Dalam: Moshang T, penyunting. Pediatric
9. Drash AL. Diabetes mellitus in the child. Dalam: Lifshitz F, penyunting. Pediatric Endocrinology. Edisi ke-3. New York: Marcel Dekker; 1996.h.555-628.

10. Masharani U, Karam JH, German MS. Pancreatic hormones \& diabetes mellitus. Dalam: Greenspan FS, Gardner DG, penyunting. Basic and clinical endocrinology. Edisi ke-7. New York: McGraw-Hill; 2004.h.669-714.

11. Diabetes mellitus. Diunduh dari: http://www. pharmerica. com/resource/Docs/20030408 DiabEpid.pdf.

12. Daneman D. Farmakologi klinik insulin. Dalam: Radde IC, MacLeod SM. Suyono J, alih bahasa. Masyrof M, editor. Farmakologi dan terapi pediatri. Jakarta: Hipokrates; 1998.h.482-92.

13. Insulin Therapy in children. Diunduh dari http:// 
www.pediatriconcall.com/fordoctor/Diseasesand Condition/ insulin_therapy.asp-72k.

14. Burdick J, Chase HP, Slover RH. Missed insulin meal boluses and elevated hemoglobin A1c levels in children receiving insulin pump therapy. Pediatrics 2004; 113:e221-4.

15. Rossetti P, Pampanelli S, Fanelli C. Intensive replacement of basal insulin in patients with type 1 diabetes given rapid-acting insulin analog at mealtime. Diabetes Care 2003; 26:1490-6.

16. Kaplan W, Rodriguez LM, Smith OE, Haymond MW, Heptulla RA. Effects of mixing glargine and short acting insulin analogs on glucose control. Diabetes Care 2004; 27:2739-40.

17. Murphy NP, Keane SM, Ong KK. Randomized crossover trial of insulin glargine plus lispro or NPH insulin plus regular human insulin in adolescents with type 1 diabetes on intensive insulin regimen. Diabetes Care 2003; 26:799-804.

18. Weintrob N, Benzaquen H, Galatzer A. Comparison of continuous subcutaneous insulin infusion and multiple daily injection regimens in children with type 1 diabetes: a randomized open srossover trial. Pediatrics 2003;
112:559-613.

19. Maniatis AK, Klingensmith GJ, Slover RH, Mowry CJ, Chase HP. Continuous subcutaneous insulin infusion therapy for children and adolescents: an option for routine diabetes care. Pediatrics 2001; 107:351-6.

20. Alemzadeh R, Ellis JN, Holzum MK, Parton EA, Wyatt DT. Beneficial effects of continuous subcutaneous insulin infusion regimen using insulin glargine in type 1 diabetes. Pediatrics 2004; 114:e91-5.

21. Plotnick LP, Clark LM, Brancati FL, Erlinger T. Safety and effectiveness of insulin pump therapy in children and adolescent with type 1 diabetes. Diabetes care 2003; 26:1142-6.

22. Benchell JW, Lomaglio JA, Seshadri R. Insulin pump therapy. A meta-analysis. Diabetes care 2003; 26:1079-87.

23. Quattrin T, Belanger A, Bohannon NJV, Schwartz SL. Efficacy and safety of inhaled insulin (Exubera) compared with subcutaneous insulin therapy in patients with type 1 diabetes. Diabetes care 2004; 27:2622-7.

24. Allen C, LeCaire T, Palta M, Daniels K, Meredith M, D'Alesso D. Risk factors for frequent and severe hypoglycemia in type 1 diabetes. Diabetes care 2001; 24:1878-81. 